\title{
Superficial Cryotherapy Versus Intralesional Corticosteroid Injection In Alopecia Areata: A Comparative Clinical And Dermoscopic Study
}

Afaf Ibrahiem Ahmad Mohammed, Asmaa Saied Farag*, Hala S.A. Hafiz

Department of Dermatology and Venereology, Faculty of Medicine for Girls, Al-Azhar University, Cairo, Egypt *Corresponding author: Asmaa Saied Farag, Mobile: (+20) 01111138832, E-Mail: assmaa_saied@yahoo.com

\begin{abstract}
Background: Alopecia areata (AA) is a common, non-scarring type of hair loss, affecting approximately $2.1 \%$ of the population. Many modalities of treatment are recommended like steroid injection, topical Immunotherapy, and several systemic therapies, but none of them can prevent or alter the course of the disease with variable degrees of improvement. Objective: To evaluate efficacy and safety of superficial cryotherapy versus intralesional corticosteroid injection in the treatment of alopecia areata. Patients and Methods: Thirty patients aged 14-58 years, with localized multiple patchy alopecia areata (at least two patches), were enrolled in this study. In each patient, one patch was treated by superficial cryotherapy via liquid nitrogen spray. This involved two treatment cycles/sessions, each lasting 3-5 seconds. The other patch was treated with intralesional steroid injection (triamcinolone acetonide $5 \mathrm{mg} / \mathrm{ml}, 0.1 \mathrm{ml} / \mathrm{cm}^{2}$. Sessions were repeated every three weeks up to three months. The target lesions were evaluated clinically using SALT score and by 2 blinded dermatologists and dermoscopically at baseline, every session, and the end of the study (one month after the last session). Results: At the end of the study, the clinical response (number of the patients with hair growth $>20 \%$ ) to superficial cryotherapy was about $83.3 \%$ ( 25 patients out of 30 patients). While in the steroid group the clinical response was about $80 \%$ ( 24 patients out of 30 patients). There was a statistically significant reduction in SALT score and dermoscopic parameters at the end of the study in both groups with no significant difference between them. There was a significant clinico-dermoscopic relation between hair regrowth and dermoscopic findings.

Conclusion: Superficial cryotherapy is an effective and safe therapeutic modality for AA with advantages of simplicity and noninvasiveness.
\end{abstract}

Keywords: Intralesional steroid, Superficial cryotherapy, Alopecia areata, Dermoscopy.

\section{INTRODUCTION}

Alopecia areata (AA) (focal alopecia) is the most common form of hair loss seen in the dermatology outpatient department comprising $25 \%$ of all alopecia cases $^{(\mathbf{1})}$. The etiopathogenesis of AA is multifactorial consisting of genetic predisposition, autoimmunity, and environmental factors ${ }^{(2)}$. AA in certain patients may progress to alopecia totalis (AT) or alopecia universalis (AU) which is up to $5-10 \%{ }^{(2)}$. Dermoscopy can be used for the diagnosis of AA and to monitor the response to therapy. The characteristic features of alopecia areata on dermoscopy are yellow dots, black dots, broken hair, exclamation mark hair, and vellus hair. These findings significantly decrease after therapy ${ }^{(3)}$.

Common modalities of treatment include topical medications as steroids, tacrolimus, anthralin, minoxidil, psoralen with ultraviolet A solution, narrowband ultraviolet B (NB-UVB), immunotherapy with diphenylcyclopropenone or squaric acid dibutyl ester (SADBE), and systemic therapy such as oral corticosteroids, levamisole, methotrexate, azathioprine and others ${ }^{(2)}$.

Intralesional corticosteroids are considered first-line treatment in localized AA involving $<50 \%$ of scalp, although painful and associated with various side effects ${ }^{(4)}$. Thus, searching for alternatives has been felt as the need of the hour ${ }^{(\mathbf{5})}$.

There are few reports of AA treated with cryotherapy ${ }^{(1)}$. The tissue response to cryotherapy ranges from an inflammatory reaction to mild or severe destruction. The response to cryotherapy can be divided into two mechanisms: Early effect and a delayed effect. The early effect is due to the formation of ice crystals which can distract cells due to direct effect or osmotic effect. The delayed effect included vascular damage, apoptosis, immunological effect, vascular constriction, platelet aggravation, ischemia, and increased permeability. So because of those effects, it can be effective in $\mathrm{AA}^{(6)}$.

This study aimed to evaluate the efficacy and safety of superficial cryotherapy versus intralesional corticosteroid injection in the treatment of alopecia areata clinically and dermoscopically.

\section{PATIENTS AND METHODS}

This comparative interventional study was conducted with patients attending the Dermatology Outpatient Clinic of Al-Zahraa University Hospital, Faculty of Medicine for Girls, Al-Azhar University, Cairo, Egypt, during the period from November 2020 to April 2021. In total, 30 adult patients with localized patchy AA were enrolled.

The study was approved by the Research Ethics Committee of the Faculty of Medicine for Girls, AlAzhar University.

Children less than 14 years old, pregnant and lactating women, patients with an active infection at the treated area, patients with premalignant or malignant lesions in the treatment area, patients with cicatricial alopecia, alopecia totalis or universalis, and patients 
who received any treatment for alopecia areata within 3 months before the study were all excluded.

All participants underwent full history taking, complete general and dermatological examination to detect site, size, and number of AA patches. The baseline assessment of alopecia areata was performed using digital camera photographs of the patches, assessment of the severity of alopecia tool (SALT) score, and dermoscopic parameters evaluation.

(SALT) score, defined as: $\mathrm{S} 0=$ no alopecia, $\mathrm{S} 1=<25 \%$ hair loss, $\mathrm{S} 2=25 \%-49 \%$ hair loss, $\mathrm{S} 3=50 \%-$ $74 \%$ hair loss, $\mathrm{S} 4 \mathrm{a}=75 \%-95 \%$ hair loss, $\mathrm{S} 4 \mathrm{~b}=96 \%-$ $99 \%$ hair loss, and $\mathrm{S} 5=100 \%$ total scalp hair loss ${ }^{(7)}$.

Under a complete aseptic condition, for each patient, two patches were chosen for the treatment and they were apart from each other's, one patch was treated with superficial cryotherapy via liquid nitrogen spray using Cryopro®. This involved two treatment cycles/session, each lasting 3-5 seconds, with one session every three weeks for three months. The other patch was treated by intralesional steroid injection of $(5 \mathrm{mg} / \mathrm{ml} /$ lesion) of triamcinolone-acetonide, using insulin syringes 0.5 -inch long 30 - gauge needle with multiple tiny injections of $0.1 \mathrm{ml} / \mathrm{cm}^{2(8)}$. Injections were repeated every three weeks, for three months.

\section{Assessment:}

Patients were assessed at baseline, every session, and at the end of the study, by (A) Digital camera photographs of the patch using Huawei nova 3i 16 megapixels digital camera (JKM-LX1, china), Photographic interpretation was done by 2 blinded dermatologists, the response was categorized into four groups: (1) Excellent response (regrowth of $>75 \%$ terminal hair). (2) Moderate response (regrowth of $>50 \%$ to $75 \%$ terminal hair). (3) Mild response (regrowth of $>20 \%$ to $50 \%$ terminal hair). (4) Poor response (regrowth of $20 \%$ or less terminal hair). (B) SALT score. (C) Dermoscopic parameters using Dermlite HUD dermoscope (3Gen, USA). (D) Patient satisfaction was also evaluated for the degree of improvement.

\section{Ethical consent:}

Approval of the study was obtained from AlAzhar University academic and ethical committee. Every patient signed informed written consent for the acceptance of the operation. This work has been carried out following The Code of Ethics of the World Medical Association (Declaration of Helsinki) for studies involving humans.

\section{Statistical Analysis:}

Data were analyzed through the Statistical Package for Social Science (IBM SPSS, Armonk, NY, IBM Corp.) version 23. The quantitative data were presented as mean, standard deviations, and ranges when their distribution found parametric and median with inter-quartile range (IQR) when non-parametric. Also, qualitative variables were presented as numbers and percentages. The comparison between groups regarding qualitative data was done by using the Chi-square test. The comparison between two independent groups with quantitative data and non-parametric distribution was analyzed by the Mann-Whitney test. The comparison between two paired groups with quantitative data and non-parametric distribution was done by using the Wilcoxon Rank test. Spearman correlation coefficients were used to assess the correlation between two quantitative parameters in the same group. The confidence interval was set to $95 \%$ and the margin of error accepted was set to $5 \%$. P-value $<0.05$ was considered significant.

\section{RESULTS}

Thirty patients with localized patchy AA were enrolled in the study. Their ages ranged from $14-58$ years with a mean \pm SD $(30.47 \pm 12.09$ years $)$. They were of both sexes (26 Males (86.7\%) and 4 females (13.3\%). Duration of current illness ranged between 1 15 months with Median (IQR) 5.5 (4 - 9). As regards the history of the studied patients, 16 patients $(53.3 \%)$ had a history of previous attacks and they were treated with topical treatment and intralesional steroids. (Table 1).

Table (1): Demographic data and characteristics of the studied patients

\begin{tabular}{|c|c|c|}
\hline & & $\mathrm{N}_{.}=\mathbf{3 0}$ \\
\hline Sex & $\begin{array}{l}\text { Females } \\
\text { Males }\end{array}$ & $\begin{array}{c}4(13.3 \%) \\
26(86.7 \%)\end{array}$ \\
\hline Age (years) & $\begin{array}{l}\text { Mean } \pm \text { SD } \\
\text { Range }\end{array}$ & $\begin{array}{c}30.47 \pm 12.09 \\
14-58\end{array}$ \\
\hline $\begin{array}{l}\text { Duration of disease } \\
\text { (months) }\end{array}$ & $\begin{array}{l}\text { Median } \\
\text { (IQR) } \\
\text { Range }\end{array}$ & $\begin{array}{l}5.5(4-9) \\
1-15\end{array}$ \\
\hline $\begin{array}{l}\text { History of Previous } \\
\text { attacks }\end{array}$ & $\begin{array}{l}\text { Negative } \\
\text { Positive }\end{array}$ & $\begin{array}{l}14(46.7 \%) \\
16(53.3 \%)\end{array}$ \\
\hline $\begin{array}{l}\text { History of Previous } \\
\text { treatment }\end{array}$ & $\begin{array}{l}\text { Negative } \\
\text { Positive }\end{array}$ & $\begin{array}{c}14(46.7 \%) \\
16(53.3 .0 \%)\end{array}$ \\
\hline
\end{tabular}

SD: standard deviation; N: number of patients IQR: interquartile range

In the cryotherapy group, SALT score before treatment ranged between 0.9-9\% with Median (IQR) $2.3(1.8-4.8) \%$ and after treatment ranged between $0.18-2.8$ with Median (IQR) $1.05(0.72-2)$ with statistically highly significant reduction at the end of the study versus baseline $(\mathbf{P}$-value $\mathbf{= 0 . 0 0 1})$. In the steroid group, the SALT score ranged between 0.54 - 14.4 with Median (IQR) $3.8(2.4-6)$ before treatment and ranged between $0.18-2.8$ with Median (IQR) $1.05(0.72-2)$ after treatment with statistically highly significant reduction at the end of the study versus baseline (Pvalue $=\mathbf{0 . 0 0 0})$. By comparing the SALT score between both groups, there was no statistically significant difference between them before treatment $(\mathbf{P}$-value $=$ $\mathbf{0 . 3 3 3})$ and after treatment $(\mathbf{P}$-value $=\mathbf{0 . 6 4 2})($ Table 2$)$. 
Table (2): Comparison between cryotherapy group and steroid group regarding SALT score before and after treatment

\begin{tabular}{|c|c|c|c|c|c|c|}
\hline & & $\begin{array}{l}\text { Cryotherapy } \\
\text { group }\end{array}$ & $\begin{array}{l}\text { Steroid } \\
\text { group }\end{array}$ & \multirow[t]{2}{*}{ Test value } & \multirow[t]{2}{*}{ P-value } & \multirow[t]{2}{*}{ Sig. } \\
\hline & & No. $=30$ & No. $=30$ & & & \\
\hline Salt score before (\%) & $\begin{array}{l}\text { Median (IQR) } \\
\text { Range }\end{array}$ & $\begin{array}{c}2.3(1.8-4.8) \\
0.9-9\end{array}$ & $\begin{array}{c}3.8(2.4-6) \\
0.54-14.4\end{array}$ & $-1.494 \neq$ & 0.135 & NS \\
\hline $\begin{array}{l}\text { Salt score (\%) at end } \\
\text { (one month after last session) }\end{array}$ & $\begin{array}{l}\text { Median (IQR) } \\
\text { Range }\end{array}$ & $\begin{array}{c}1.05(0.72-2) \\
0.18-2.8\end{array}$ & $\begin{array}{c}1.2(0.48-4.8) \\
0.24-6\end{array}$ & $-0.716 \neq$ & 0.474 & NS \\
\hline \multirow{2}{*}{ Wilcoxon Signed Ranks test } & Test value & -2.803 & -3.061 & \multirow[b]{3}{*}{$\mathrm{F}$} & \multirow[b]{3}{*}{0.333} & \multirow[b]{3}{*}{ NS } \\
\hline & P-value & 0.005 (HS) & 0.002 (HS) & & & \\
\hline Salt score before & $\begin{array}{l}\text { S0 } \\
\text { S1 } \\
\text { B0 } \\
\text { B1 }\end{array}$ & $\begin{array}{c}0(0.0 \%) \\
22(73.3 \%) \\
0(0.0 \%) \\
8(26.7 \%)\end{array}$ & $\begin{array}{c}0(0.0 \%) \\
26(86.7 \%) \\
0(0.0 \%) \\
4(13.3 \%)\end{array}$ & & & \\
\hline $\begin{array}{l}\text { Salt score at the end } \\
\text { (one month after last session) }\end{array}$ & $\begin{array}{l}\text { S0 } \\
\text { S1 } \\
\text { B0 } \\
\text { B1 }\end{array}$ & $\begin{array}{c}12(40.0 \%) \\
10(33.3 \%) \\
2(6.7 \%) \\
6(20.0 \%)\end{array}$ & $\begin{array}{c}13(43.3 \%) \\
13(43.3 \%) \\
1(3.3 \%) \\
3(10.0 \%)\end{array}$ & $\mathrm{F}$ & 0.642 & NS \\
\hline \multirow{2}{*}{ Chi-square test } & $\mathbf{X}^{2}$ & 18.786 & 18.476 & & & \\
\hline & P-value & 0.000 (HS) & 0.000 (HS) & & & \\
\hline
\end{tabular}

P-value > 0.05: Non significant; P-value < 0.05: Significant; P-value < 0.01: Highly significant

F: Fisher's Exact test; $\neq$ : Mann-Whitney test

Concerning clinical response determined by 2 blinded dermatologists; in the cryotherapy group, hair regrowth was poor in 5 patients $(16.7 \%)$, mild in 13 patients $(43.3 \%)$, moderate in 6 patients $(20.0 \%)$, and excellent in 6 patients $(20.0 \%))$ ranged between (5-90) with a median (IQR) 40 (30-70)(. While in the steroid group, there was poor hair regrowth in 6 patients $(20.0 \%)$, mild hair regrowth in 6 patients $(20.0 \%)$, moderate hair regrowth in 5 patients $(16.7 \%)$, and excellent hair regrowth in 13 patients (43.3\%) )ranged between (5-95) with a median (IQR) 70 (30-90)( with no statistically significant difference between both groups $(\mathbf{p}$-value $\mathbf{= 0 . 1 4 9})($ Table3) .

Table (3): Comparison between cryotherapy and steroid group regarding hair regrowth

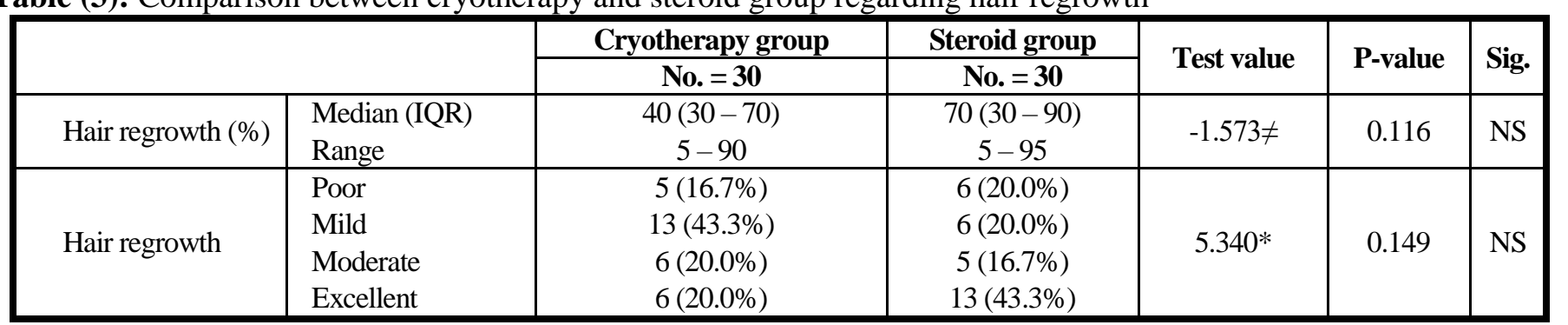

P-value > 0.05: Non significant; P-value < 0.05: Significant; P-value < 0.01: Highly significant

*: Chi-square test; $\neq$ : Ma. + nn-Whitney test $* \mathrm{NS}=$ Non significance. ${ }^{*}$ No $=$ Number.

In the cryotherapy group, No patient $(0.0 \%)$ was very unsatisfied, 6 patients $(20.0 \%)$ were unsatisfied, 7 patients (23.3\%) were neither satisfied nor unsatisfied, 12 patients $(40.0 \% \%)$ were satisfied and 5 patients were $(16.7 \%)$ very satisfied ranging 2-5 with a median (IQR) $4(3-4)$; while in the steroid group, there was 1 patient (3.3\%) was very unsatisfied, 4 patients $(13.3 \%)$ unsatisfied, 6 patients $(20.0 \%)$ were neither satisfied nor unsatisfied, 10 patients $(33.3$ $\%$ ) were satisfied and 9 patients were (30.0\%) very satisfied ranging 1-5 with a median (IQR) 4 (3-5) with statistically no significant difference between both groups $(\mathbf{p}$-value $\mathbf{= 0 . 6 2 5})($ Table 4$)$.

Table (4): Comparison between cryotherapy group and steroid group regarding patient satisfaction

\begin{tabular}{|c|c|c|c|c|c|c|}
\hline & & Cryotherapy group & Steroid group & \multirow{2}{*}{ Test value } & \multirow{2}{*}{ P-value } & \multirow{2}{*}{ Sig. } \\
\hline & & No. $=30$ & No. $=30$ & & & \\
\hline & $\begin{array}{l}\text { Median (IQR) } \\
\text { Range }\end{array}$ & $\begin{array}{c}4(3-4) \\
2-5\end{array}$ & $\begin{array}{c}4(3-5) \\
1-5\end{array}$ & $-0.869 \neq$ & 0.385 & NS \\
\hline $\begin{array}{l}\text { Patient } \\
\text { satisfaction } \\
\text { (Likert scale) }\end{array}$ & $\begin{array}{l}\text { Very unsatisfied } \\
\text { Unsatisfied } \\
\text { Neither satisfied nor unsatisfied } \\
\text { Satisfied } \\
\text { Very satisfied }\end{array}$ & $\begin{array}{l}0(0.0 \%) \\
6(20.0 \%) \\
7(23.3 \%) \\
12(40.0 \%) \\
5(16.7 \%)\end{array}$ & $\begin{array}{c}1(3.3 \%) \\
4(13.3 \%) \\
6(20.0 \%) \\
10(33.3 \%) \\
9(30.0 \%)\end{array}$ & $\mathrm{F}$ & 0.652 & NS \\
\hline
\end{tabular}

P-value > 0.05: Non significant; P-value < 0.05: Significant; P-value < 0.01: Highly significant

F: Fisher's Exact test; $\neq$ : Mann-Whitney test 
In both groups, hair regrowth showed a statistically significant positive correlation with SALT score reduction and Likert scale and showed statistically significant negative correlation with duration of the disease while no statistically significant correlation was found with the age of the studied patients (Table 5).

Table (51): Correlation of hair regrowth with SALT score reduction, age of patients, duration of the disease, and Likert scale among studied cases:

\begin{tabular}{|l|c|c|c|c|c|c|}
\hline \multirow{2}{*}{} & \multicolumn{9}{|c|}{ Hair regrowth (\%) } \\
\cline { 2 - 7 } & \multicolumn{2}{|c|}{ Both groups } & \multicolumn{2}{|c|}{ Cryotherapy group } & \multicolumn{2}{c|}{ Steroid group } \\
\cline { 2 - 7 } & $\mathbf{R}$ & $\mathbf{P}$-value & $\mathbf{R}$ & P-value & \multicolumn{1}{|c|}{ R } & P-value \\
\hline SALT score reduction & $\mathbf{0 . 6 7 3} * *$ & $\mathbf{0 . 0 0 1}$ & $\mathbf{0 . 4 8 3}$ & $\mathbf{0 . 0 1 7}$ & $\mathbf{0 . 8 2 1} * *$ & $\mathbf{0 . 0 0 1}$ \\
\hline Age & 0.040 & 0.759 & 0.175 & 0.355 & -0.082 & 0.667 \\
\hline Duration (months) & $\mathbf{- 0 . 2 7 2}$ & $\mathbf{0 . 0 3 6}$ & -0.225 & 0.231 & -0.309 & 0.097 \\
\hline Patient satisfaction (Likert scale) & $\mathbf{0 . 8 3 0} * *$ & $\mathbf{0 . 0 0 1}$ & $\mathbf{0 . 6 3 8} * *$ & $\mathbf{0 . 0 0 1}$ & $\mathbf{0 . 9 5 5} * *$ & $\mathbf{0 . 0 0 1}$ \\
\hline
\end{tabular}

P-value > 0.05: Non significant; P-value < 0.05: Significant; P-value < 0.01 : Highly significant

Spearman correlation coefficient

Regarding dermoscopic findings, in cryotherapy group, there was statistically significant reduction in yellow dots $(\mathrm{P}$-value $=0.004)$, black dots $(\mathrm{P}$-value $=0,001)$, exclamation marks $(\mathrm{P}$-value $=0.000)$, broken hairs $(\mathrm{P}$-value $=0.005)$ and vellus hairs $(\mathrm{P}$-value $=1.000)$ at the end of sessions; similarly in steroid group, there was statistically significant reduction at the end of sessions in yellow dots $(\mathrm{P}$-value $=0.000)$, black dots $(\mathrm{P}$-value $=0.003)$, exclamation marks $(\mathrm{P}-$ value $=0.002)$, broken hairs $(\mathrm{P}$-value $=0.000)$ and vellus hairs $(\mathrm{P}$-value $=0.114)$. By comparing the reduction of dermoscopic findings in both groups at the end of the study we found that there was no statistically significant difference between them in yellow dots, broken hair, exclamation mark, and black dots (p-value $=0.069,0.112,0.640$, and 0.488 respectively) but there was a statistically significant difference between them in vellus hair which was positive in 24 patients $(80.0 \%)$ in cryotherapy group compared to 15 patients $(50.0 \%)$ in steroid group after treatment $(\mathrm{p}$-value $=0.015)$ (Table 6).

Table (6): Dermoscopic finding in cryotherapy group versus steroid group before and after treatment:

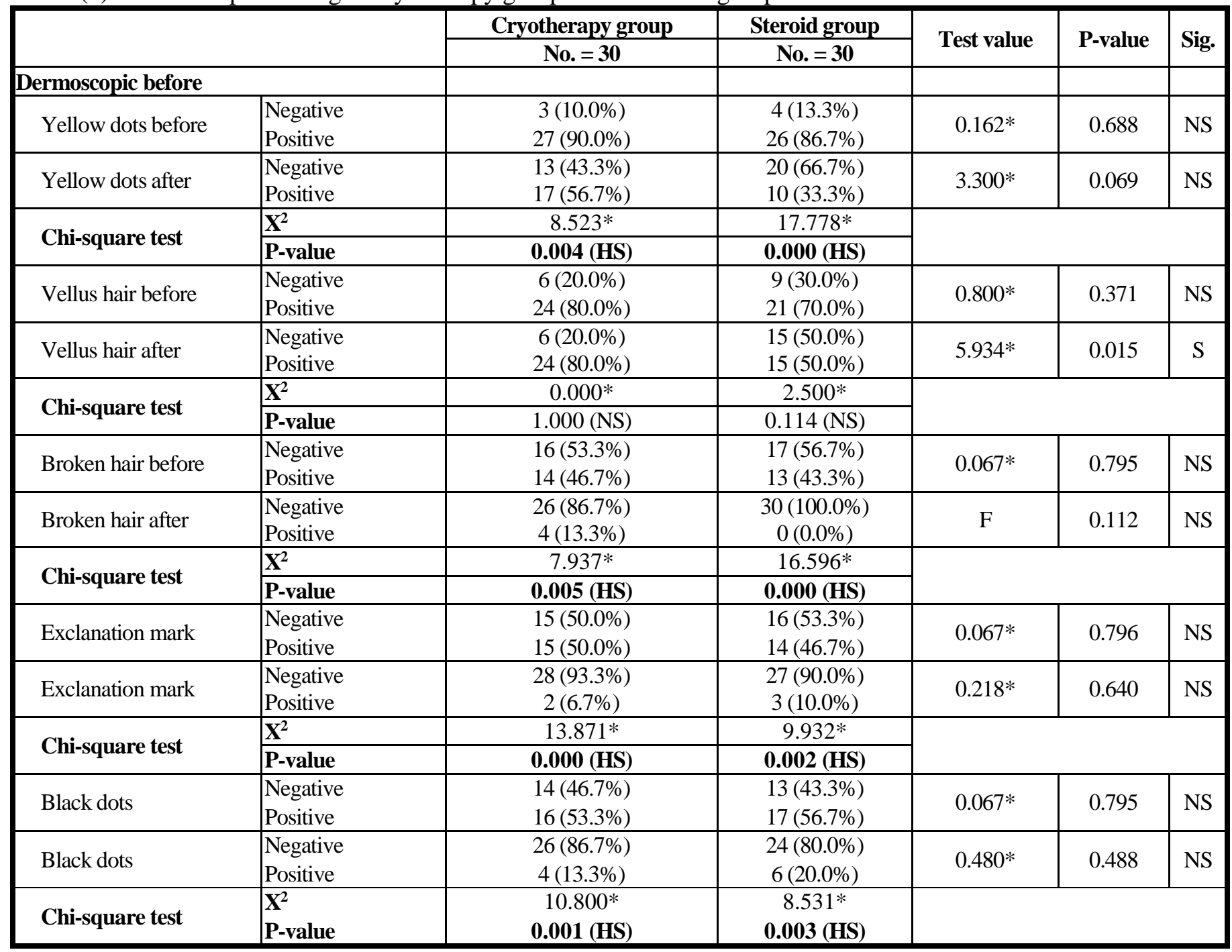

P-value > 0.05: Non significant; P-value < 0.05: Significant; P-value < 0.01: Highly significant.*: Chi-square test; F: Fisher's Exact test 
Clinical and dermoscopic photos of patients at baseline and the end of the study showing improvement of AA lesions

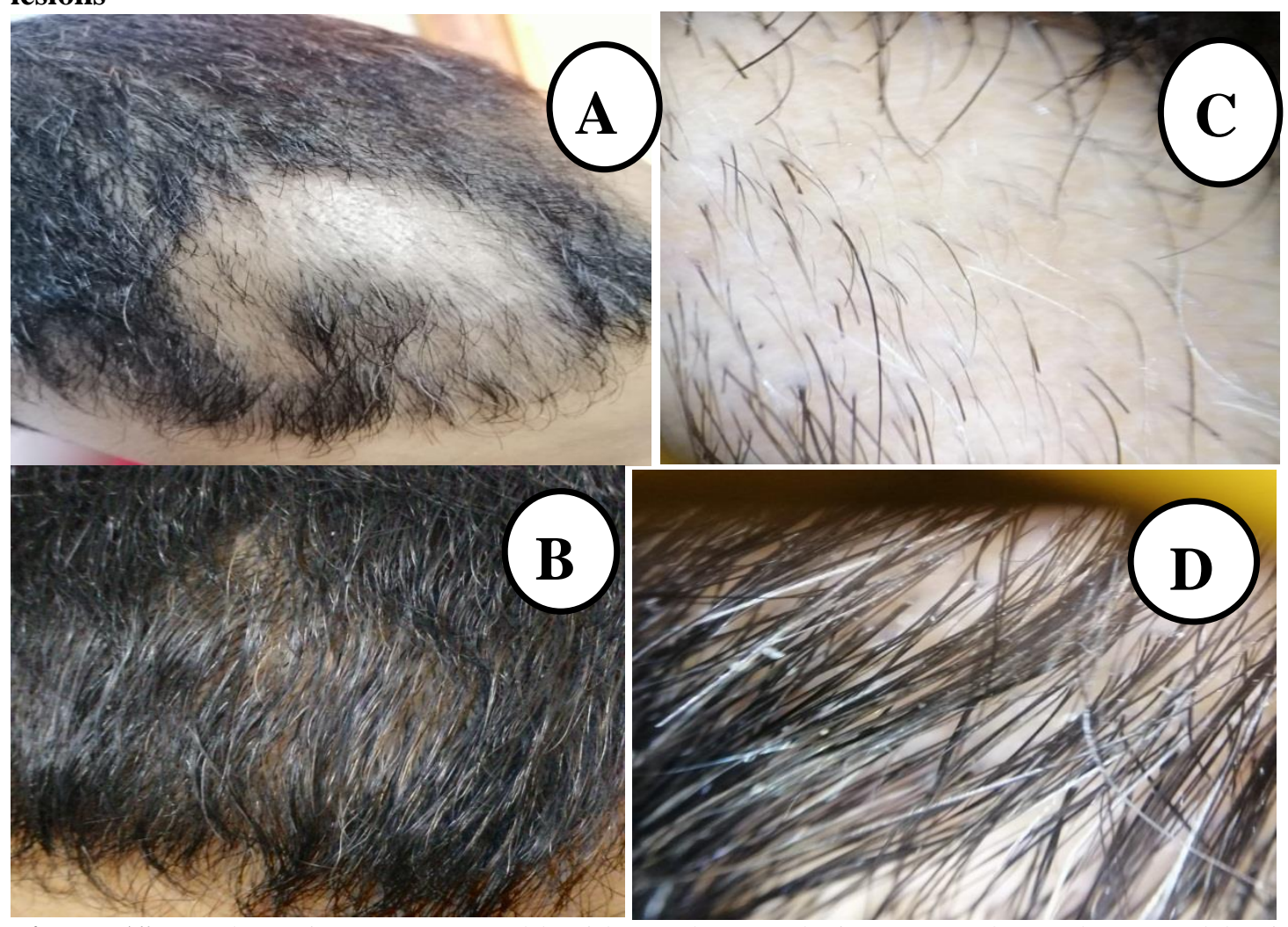

Figure (1): Male patient 35 years old with patchy AA lesions over the scalp treated by intralesional injection of triamcinolone acetonide. (A) Before treatment with the SALT score of about 7\% S1. (B) At the end of the study with excellent hair growth ( hair regrowth $\geq 75 \%$ ) and SALT score became S0. (C) Dermoscopic photo before treatment showing broken hair, exclamation mark vellus hair, and black dot. (D) Dermoscopic photo at the end of the study showing the disappearance of all dermoscopic findings and growth of terminal hair.

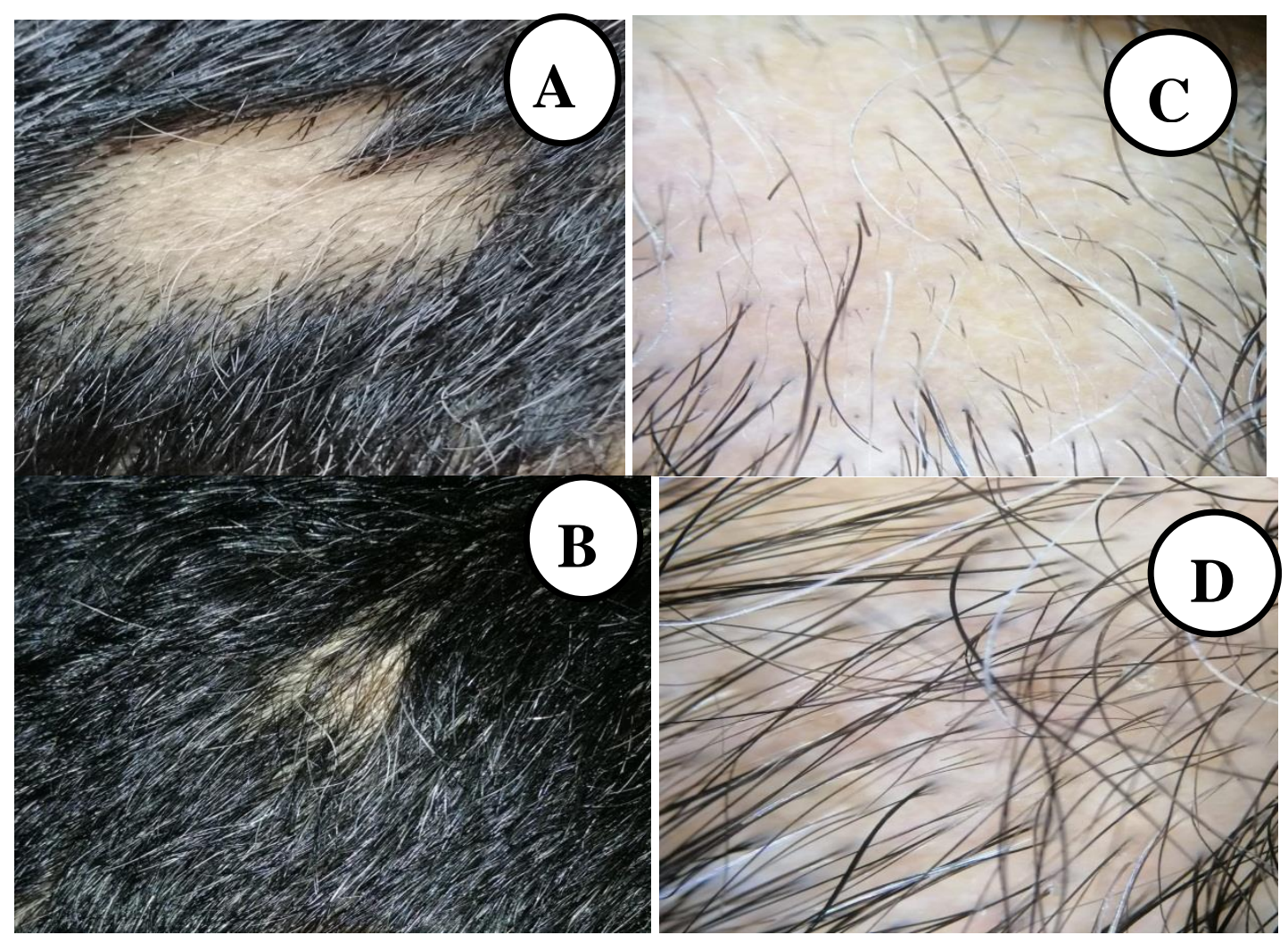

Figure (2): Male patient 35 years old with patchy AA lesions over the scalp treated by superficial cryotherapy. (A) Before treatment with the SALT about $1.2 \%$ S1. (B) At the end of the study with excellent hair regrowth (hair regrowth $\geq 75$ scores of \%) and SALT score became S0. (C) Dermoscopic photo before treatment showing yellow dots, broken hair, exclamation mark, and vellus hair. (D) Dermoscopic photo at the end of the study showing the disappearance of all dermoscopic findings and growth of terminal hair. 


\section{DISCUSSION}

The main etiology for the occurrence of AA is not clear, the evidence is in favor of an autoimmune disease. Disease changes with genetic factors, and is exacerbated by the stress ${ }^{(\boldsymbol{9 )}}$. Conventional treatments of AA include intralesional steroid, photochemotherapy, and systemic steroid therapy. Cryotherapy can also be useful in the treatment of $\mathrm{AA}^{(\mathbf{1 0})}$.

We conducted this study to evaluate the efficacy and safety of superficial cryotherapy as a therapeutic modality for localized AA and to compare it to one of the most commonly used treatments for AA which is (ILCS).

Concerning clinical response determined by the 2 blinded dermatologists. In the cryotherapy group, there was excellent hair regrowth in 6 patients $(20.0 \%)$, moderate hair regrowth in 6 patients (20.0\%), mild hair regrowth in 13 patients $(43.3 \%)$, and poor hair regrowth in 5 patients $(16.7 \%)$ ranged between $(5-90 \%)$ with a median (IQR) 40 (30-70); while in steroid group there was excellent hair regrowth in 13 patients $(43.3 \%)$, moderate hair regrowth in 5 patients (16.7\%), mild hair regrowth in 6 patients (20.0\%)and poor hair regrowth in 6 patients $(20.0 \%)$ ranged between $(5-95 \% \%)$ with a median (IQR) 70 (30-90).

In our study, the overall clinical response (number of the patients show hair regrowth $>20 \%$ ) of AA lesions treated with cryotherapy was $83.3 \%$ and this was better than the results of Kim et al. ${ }^{(11)}$ that showed that superficial cryotherapy induced regrowth of hair in $66.7 \%$ of patients. Similarly, Hong et al. ${ }^{(12)}$ in their Korean study done on 153 patients with AA, $68.6 \%$ of patients showed a therapeutic response after 12 weeks of treatment with superficial cryotherapy using liquid nitrogen. In Myungsoo and Lee ${ }^{(13)}$ study, $60.9 \%$ of the patients were classified as responders to cryotherapy. Also in Abdel-Majid et al. ${ }^{(14)}$ study, the overall clinical response of AA lesions treated with cryotherapy was $65 \%$.

Another study using a different cryotherapy technique was done in 2013 by Radmanesh and AzarBeig ${ }^{(15)}$ on 44 patients with AA or AT treated with a closed contact $\mathrm{CO} 2$ system for 8 weeks. They suggest that cold-induced inflammation may alter the immunologic process and structural components of the hair follicle responsible for AA. In spite of the closed contact technique and the longer duration of therapy, their study showed a positive therapeutic response in 29 (65.9\%) of 44 patients compared with 25 (83.3\%) of 30 patients in our study.

However our results were lower than that of Lei $\boldsymbol{e t}$ al. ${ }^{(16)}$ who tried cryotherapy on patients with AA once weekly for 4 weeks, $97.2 \%$ of the patients were improved compared with $83.3 \%$ in our study. This could be explained by a large number of the studied patients (119 AA patients), the different cryotherapy techniques (a cotton swab technique), and the short interval between sessions (session every week).
In our study, there was no statistically significant difference between the cryotherapy group and steroid group as regards hair regrowth (p-value $\mathbf{0 . 1 4 9}$ ).

Our results disagree with Amirnia et al. ${ }^{(18)}$ study, in their study, $83.3 \%$ of patients treated with ILCS showed a good response compared to only $56.7 \%$ of patients treated with superficial cryotherapy. This could be due to bias from the subjective assessment of the outcome as their results were dependent only on the subjective clinical response assessment of the AA patches.

However, our results agree with Gita et al. ${ }^{(17)}$ who compared the efficacy of cryotherapy with liquid nitrogen and topical $0.1 \%$ betamethasone in the treatment of AA in 40 patients and found that the overall response rate of patches was $88 \%$ in the cryotherapy group and $90 \%$ in the clobetasol group.

In the current study, there was a statistically significant reduction in SALT score after treatment in both groups with no statistically significant difference between them $(\mathbf{P}$-value $\mathbf{= 0 . 6 4 2})$.

In both groups, the reduction in SALT score after treatment was $46.7 \%$ which was higher than the mean SALT score change percentage of $40.7 \%$ obtained by Jun and Lee ${ }^{(19)}$ who combined superficial cryotherapy using liquid nitrogen, and prednicarbate $0.25 \%$ solution and lower than than the mean SALT score change percentage of $54.49 \%$ obtained by Aboeldahab et al. (20) who used superficial cryotherapy by dimethyl ether and propane mixture (DMEP). In our study, we used dermoscopy to provide more objective results. There was a significant improvement in all dermoscopic findings of AA observed from the first session and become more significant at the end of the study. This agrees with the study of Srivastava et al. (21) and Ganjoo and Thappa (1) who demonstrated early response to intralesional corticosteroid by dermoscopy, where $67 \%$ of the patches showed maximum dermoscopic change by 8 weeks and $91 \%$ of the patches showed maximum dermoscopic change by 12 weeks.

In our study, there was statistically significant clinico-dermoscopic relation between hair regrowth and dermoscopic findings at the end of the study, where hair regrowth was more in cases with negative dermoscopic findings of AA as in the study of Srivastava et al. (21) who reported significant clinico-dermoscopic relation between regrowth scale and dermoscopic findings reduction.

\section{Conclusion:}

Cryotherapy is a safe and effective modality in the treatment of patchy AA and is better to be selected as a treatment option especially in pediatric patients with AA or when there is a contraindication to ILCS injection.

\section{Recommendations:}

Further studies with a larger number of patients, more sessions with short interval periods, and long-term follow-up are recommended to validate our results. 
Comparing different methods of cryotherapy such as cryospray and cotton-tipped cryotherapy is recommended to choose the method with the best treatment outcome.

Financial support and sponsorship: Nil.

Conflict of interest: Nil.

\section{REFERENCES}

1. Ganjoo S, Thappa D (2013): Dermoscopic evaluation of therapeutic response to an intralesional corticosteroid in the treatment of alopecia areata. Ind $\mathbf{J}$ Dermatol Venereol Leprol., 79:408.

2. Seetharam K (2013): Alopecia areata: An update. Indian J Dermatol Venereol Leprol., 79: 56375.

3. Inui $S$, Nakajima T, Nakagawa $K$ et al. (2008): Clinical significance of dermoscopy in alopecia areata: Analysis of 300 cases. Int J Dermatol., 47:688-693

4. Kaur S, Mahajan B, Mahajan $R$ (2015): Comparative evaluation of intralesional triamcinolone acetonide injection, narrow band ultraviolet $\mathrm{B}$, and their combination in alopecia areata. Int J Trichol., 7(4): 148- 155.

5. El-Husseiny R, Elframawy S, Abdallah M (2020): Comparative study between fractional carbon dioxide laser vs intralesional steroid injection in the treatment of alopecia areata. Dermatologic Therapy, 33(4): 13742-48.

6. James W, Berger T, Elston D (2011): Andrew's diseases of the skin: Clinical Dermatology. Elsevier Health Sciences, 10: 403-15.

7. Olsen E, Hordinsky M, Price $V$ et al. (2004): Alopecia areata investigational assessment guidelinesPart II. Journal of the American Academy of Dermatology, 51:440-447.

8. Alkhalifah A, Alsantali A, Wang E et al. (2010): Alopecia areata update Part II Treatment. J Am Acad Dermatol., 62:191-202.

9. Amirnia M, Mahmoudi S, Karkon-Shayan F et al. (2015): Comparative study of intralesional steroid injection and cryotherapy in alopecia areata. Nigerian medical journal: journal of the Nigeria Medical Association, 56(4), 249.

10. Sayed D, Allam A, Abdel-Majid E (2020): Superficial cryotherapy versus topical psoralen and ultraviolet $\mathrm{A}$ in the treatment of alopecia areata: a randomized, controlled trial. Journal of the Egyptian Women's Dermatologic Society, 17(2): 98-103.

11. Kim T, Kim D, Kim S (1994): Effect of cryotherapy with liquid nitrogen on alopecia areata. Korean $\mathrm{J}$ Dermato., 32: 421-426.

12. Hong $S$, Jeon $S$, Lee $W$ (2006): A retrospective study of the effect of superficial cryotherapy on alopecia areata. Korean J Dermatol., 44:274-280.

13. Myungsoo J, Lee W (2017): Therapeutic Effect of Superficial Cryotherapy on Alopecia Areata: A Prospective, Split-scalp Study in Patients with Multiple Alopecia Patches. Annals of Dermatology, 29: 722727.

14. Abdel-Majid E, Abdel-Kadera D, Allamb A (2018): Liquid nitrogen cryotherapy in the treatment of alopecia areata: an Egyptian study. Journal of Current Medical Research and Practice, 3: 187-190.

15. Radmanesh M, Azar-Beig M (2013): Cryotherapy as an alternative therapy for the treatment of recalcitrant alopecia areata. Iran J Dermatol., 16:49-52.

16. Lei Y, Nie Y, Zhang J et al. (1991): Effect of superficial hypothermic cryotherapy with liquid nitrogen on alopecia areata. Arch Dermatol., 127:1851-1852.

17. Gita F, Mohammadreza R (2013): Liquid nitrogen cryotherapy vs. betamethasone lotion in the management of alopecia areata. J Clin Med Res., 5:18 22.

18. Amirnia M, Mahmoudi S, Karkon-Shayan F et al. (2015): Comparative study of intralesional steroid injection and cryotherapy in alopecia areata. Nigerian Medical Journal: Journal of the Nigeria Medical Association, 56(4), 249.

19. Jun M, Lee W (2017): Therapeutic effect of superficial cryotherapy on alopecia areata: a prospective, split-scalp study in patients with multiple alopecia patches. Ann Dermatol., 29:722-727.

20. Aboeldahab S, Nada E, Assaf H et al. (2021): Superficial cryotherapy using dimethyl ether and propane mixture versus micro needling in the treatment of alopecia areata: A prospective single-blinded randomized clinical trial. Dermatologic Therapy, 21: 15044-48.

21. Srivastava S, Goyal S, Dhillon K et al. (2017): Dermoscopic evaluation of therapeutic response to intralesional triamcinolone acetonide in the treatment of Alopecia areata. Int J Advan Medic., 4: 1175-79. 